chemical and agricultural science, new materials will be made a vailable while a general summary of scientific facts and discoveries will form an important feature." An editorial committee, comprising some of the foremost scientific men in Canada, has been appointed and the publication remains, as before, under the "auspices" of the Natural History Society of Montreal. The number just received in this country contains, in addition to a batch of articles on different subjects in natural history, one on the partial eclipse of the sun in August last, as observed at Montreal, by Dr. Smallwood.

AN interesting report on the ravages of the Borer in Coffee estates has jutst been published by George Bidie, M.B., F.R.G.S. The coffee plant, as is well known, is not indigenous to Southern India, but was first introduced into India upwards of two centuries ago, by a Mussulman pilgrim, Bababooden, who on his return from Mecca brought a few berries in his wallet, and taking up his abode in the hills of Mysore, planted them near his tent, and from these the greater portion of the coffee now growing in Southern India has been derived. It is a native of Caffa in Sonthern Abyssinia. It is now largely cultivated in Mysore, Cuddoor, Coorg, and other parts along the crests and slopes of the Ghauts. It is a remarkably hardy plant, thriving at various elevations, and under the most different conditions of moisture, soil, and temperature. It is, however, liable to the attacks of certain insects, amongst which the Borer is the most formidable. This is shown by Dr. Bidie to be the larva of a beetle belonging to the Cerambycidæ, and termed the Xylotrechus quadrupes. The female lays its eggs in the bark of the plants, hot sunshine favouring their hatching. The larva immediately pierces the bark, and derives its nourishment from the more juicy layers, producing, by the damage it causes, exhaustion of the tree and loss of the crop. The whole duration of the life of the animal from the deposition of the ovum to the death of the beetle does not exceed twelve months. The animal appears to be indigenous, and the causes that have led to the great increase in its ravages during the last few years are drought, want of shade, bad culture, destruction of forest trees in which the insect used to live, and departure of some of its enemies.

THE following changes are announced in the arrangements of the staff of St. Bartholomew's Hospital. One assistant-physician is to have charge of the casualty department; three casualty physicians are to act with him; and one casualty surgeon is to superintend the surgical side. The house-surgeons will have charge of casualty patients.

THE Geographical Society of St. Petersburg has decided to send a scientific expedition into Manchouria and Eastern. Mongolia, for the purpose of making archæological and ethnographical researches in those countries. The expedition is to start next April, under the direction of the Archimandrite Palladiy, chief of the Russian mission at Pekin. It is said that the Emperor has contributed 5,000 roubles towards the expenses of the expedition.

THE rainfall of the year ending December 31,1869 , as taken in the neighbourhood of Charing Cross, is registered as follows:-

$$
\begin{aligned}
& \text { Height of gauge above ground. Number of inches fallen } \\
& 6 \text { feet } 64: \therefore: \therefore: \vdots 23^{2} 760
\end{aligned}
$$

Mr. E. W. Hilgard, in his Geological Reconnaissance of Louisiana, finds reason for the assumption that " the Gulf coast has in late quaternary times suffered a depression to the extent of at least 900 feet-perhaps more---and during the terrace epoch a contrary motion to the extent of about half that amount." Elsewhere he remarks, "the age of the great gypsum formation has been the subject of much discussion. It has always seemed to me that the great extent of the area over which the cretaceous beds and underlying gypsum are known to be co- extensive, went far to prove that they belonged substantially to the same epoch. Whatever weight may attach to this argument it is greatly enhanced when we find the crystalline limestone and underlying gypsum not only reappearing in northern Louisiana, but actually accompanying each other beneath the waters of the Gulf of Mexico. Whether the volcanic agencies which even now so frequently disturb that great basin, have been instrumental in reducing the sulphur, distilling the petroleum and crystallising the rock salt of southern Louisiana, may be more profitably discussed when more extensive excavations shall have given us an opportunity of closer inspection of the facts."

IN reference to the electro-deposition of nickel, M. Bouilhet states that Jacobi published a method of obtaining thick coatings of nickel by using perfectly neutral solutions. Cosmos points cut that nickel is especially abundant in Spain.

\section{ON THE TEMPERATURE AND ANIMAL LIFE OF THE DEEP SEA*}

\section{II.}

DURING the first and second cruises of the Porcupine, the temperature of the eastern border of the great North Atlantic basin was examined at various depths between from 54 to 2,435 fathoms, and in widely different localities, ranging from lat. $47^{\circ}$ to lat. $55^{\circ}$. The bottom-temperature was as" certained at thirty stations, and serial soundings were taken at seven stations; making the total number of observations eightyfour. (Table II., p. 20.) Amongst all these the coincidence of temperatures at corresponding depths is extraordinarily close; the chief differences showing themselves in the temperature of the surface and of the stratum immediately beneath it. A decided superheating is observable in this superficial stratum, not extending to a depth of much more than 70 or 80 fathoms, and more considerable at the southern than at the northern stations. Whether this "superheating" is entirely due to the direct influence of solar heat, or depends in any degree on an extension of the Gulf Stream as far as the southern part of the area examinetl, is a question which can only be resolved by the determination of its relative amount at different seasons. Between 500 and 500 fathoms, the rate of decrement is very slow, averaging only about $3^{\circ}$ in the whole, or three-fourths of a degree for every 100 fathoms; and this body of water has a temperature so much above the isotherm of the northern stations at which the observations were macle, as decidedly to indicate that it must have found its way thither from a southern source. Between 500 and 750 fathoms, however, the rate of decrease becomes much more rapid, the reduction being $54^{\circ}$, or above $2^{\circ}$ per 100 fathoms; while between 750 and roo0 fathoms it amounts to $3 . \mathrm{I}^{\circ}$, bringing down the temperature at the latter depth to an average of $38.6^{\circ}$. Beneath this there is still a slow progressive reduction. with increase of depth, the temperature falling a little more than $2^{\circ}$ between 1000 and 2,435 fathoms; so that at the lastnamed depth, the greatest at which it was ascertained, it was $36.5^{\circ}$. - Thus it is obvious either that the vast body of water occupying the deeper half of the Atlantic basin has been itself derived from a colder region, or that its temperature has been reduced by the diffusion through it of frigid water from a Polar source. The latter supposition best accords with the gradual depression. of temperature exhibited between 500 and I000 fathoms, which corresponds with the "stratum of intermixture" of the cold area.

The temperature soundings recently taken by Commander Chimmo, R.N., and Lieutenant Johnson, R.N., at various points in the North Atlantic basin, when the requisite corrections are applied for the influence of pressure on the bulbs of the unprotected thermometers employed by them, give results which are remarkably accordant with our owis; so that it may be stated with confidence that the temperature of the deeper parts of the North Atlantic sea-board is but a very few degrees above the freezing-point.

Now a glance at the North Polar region, as laid down either on a globe, or any projection of which the Pole is the centre, shows that the Polar basin is so much shut in by the northern shores of the European, Asiatic, and American continents,

* A Lecture delivered at the Royal Institution (continued from p. 490). 
that its only communication with the North Atlantic basinbesides the circuitous passages leading into Hudson's and Baffin's Bays-is the space which intervenes between the eastern coast of Greenland and the north-western portion of the Scandinavian peninsula. If, therefore, there be any such general interchange of Polar and Equatorial water as that for which we have argued, the Arctic current must flow through the deeper portions of this interspace, at the north of which lies Spitzbergen, whilst Iceland and the Faroes lie in the middle of its southerly expanse. Now in the channel that lits between Greesland and Iceland; the depth is such as to give a free passage to such a frigid stream; but between Iceland and the Faroe Islands there is no depth so great as 300 fathoms at any part, except in a narrow channel at the south-east corner of Iceland; so that an eftectual barrier is thus interposed to any movement of frigid water at a depth exceeding this. A similar barrier is presented, not merely by the platean on which the British Islands rest, but also by the bed of the North Sea; the shallowness of which must give to such a movement a not less effectual check than would be afforded by an actual coast-line uniting the Shetland Islands and Norway. Consequently, it is obvious that a flow of ice-cold water, at a depth exceeding 300 fathoms from the surface, down the north-eastern portion of this interspace, can only find its way southwards through the deeper portion of the channel between the Faroe and shetland Islands; which will turn it into a W. S. W direction between the Faroe Islands and the north of Scotland, and finally discharge such part of it as has not been neutralised by the opposing stream coming up from the southwest, into the great North Atlantic basin, where it will meet the Icelandic and Greenland currents, and unite with them in diffusing frigid waters through its deeper portion. In thus spreading itself, however, the frigid water will necessarily mingle with the mass of warmer water with which it meets, and will thus have its own temperature raised, whilst lowering the general temperature of that mass; and hence it is that we do liot find the temperature of even the greatest depths of the Atlantic basin nearly so low as that of the comparatively shallow channel which feeds it with Arctic water.

It may be 'questioned, however, whether the whole body of Aretic water that finds its way through the channels just indicated; could alone maintain so considerable a reduction in the temperature of the enormous mass which lies below r,ooo fathoms in the Atlantic basin; subject as this must be to continual elevation by the surface-action of the sun on its sonthern portion. And as the few reliable observations on deep-sea temveratures under the equator indicate that even there a temperature not much above $32^{\circ}$ prevails, it seems probable that part of the cnoling effect is due to the extension of a flow of frigid water from the Antarctic Pole, even north of the Tropic of Cancer. Of such an extension there is evidence in the temperature-soundings recently taken in H.M.S. Hydra between Aden and Bombay, where the cooling influence could scarcely have been derived from any other source than the Antarctic area.*

The unrestricted communication which exists between the Antarctic area and the great Southern ocean-basins would involve, if the doctrine of a general Oceanic circulation be admitted, a much more considerable interchange of waters between the Antarctic and Equatorial areas, than is possible in the Northern hemisphere. And of such a free interchange there scems adequate evidence; for it is well known to navigators that there is a perceptible "set" of warm surface-water in all the Southern oceans towards the Antarctic Pole ; this "set" being so decided in one part of the Southern Indian Ocean, as to be compared by Captain Maury to the Gulf Stream of the North Atlantic. + Conversely, it would appear from the application of the necessary pressure-correction to the temperatures taken in 'Sir James Ross's Antarctic expedition, the yoyage of the $V$ entits, \&ce, at depths greater than I, ooo fathoms, that the bottom-temperature of the deepest parts of the Southern Oceanic basin really approaches the freezing-point, or is even below it And if the temperature of the deeper portion of the North Pacific Ocean should be found to exhibit a depression at all corresponding to that of the North Atlantic, it must be attributed entirely to the extension of this Antarctic flow; since the depth

* The lowest temperature actually observed in these soundings was $361^{\circ}$. The temperature of $33^{\circ}{ }^{\circ}$ given in the previous discourse, as existing below $x, 800$ fathoms, proves to have been only an estimate formed by Capt. Shortland sinder the idea that the rate of reduction observed at smaller depths would continue uniform to the bottom, which the serial soundings of the Porcupine

prove "Physical Geography of the Sea," $\$$ 748-750. of Behring's Strait, as well as its breadth, is so small as to permit no body of Arctic water to issue through that channel.

If further observatious should substantiate the general diffusion of a temperature not much above the freezing-point over the deepest portions of the ocean-bed, even in Intertropical regions, as a result of a general deep movement of Polar waters towards the Equator, furming the complement of the surface-movernent of Equatorial water towards the Poles, it is obvious that such diffusion must exert a very important influence on the distribution of animal life; and, in particular, that we may expect to meet with forms which have hitherto been reputed essentially Arctic; in the deep seas of even the Intertropical region, and again in the shallower water of the Antarctic area. Such, there is strong reason to believe, will prove the case. In his recent annual address as President of the Royal Society, Sir Edward Sabine cites observations on this point made by Sir James Ross in his Antarctic expedition, as confirmatory of the view entertained by that distinguished navigator, "that water of similar temperature to that of the Arctic and Antarctic seas exists in the depths of the intermediate ocean, and may have formed a channel for the dissemination of species." The "similar temperature" believed by Sir James Ross to have had this general prevalence, seems to have been $39^{\circ}$; whereas the observations made in the Porcupine expedition distinctly prove that a temperature even below $30^{\circ}$ may be conveyed by Polar streams far into the temperate zone, and that the general temperature of the deepest part of the North Atlantic sea-bed has more of a Polar character than he supposed.

Again, the deep-sea dredgings of the Porcutpine expedition have shown that many species of mollusks and crustacea previously supposed to be purely Arctic, range southwards in deep water as far as those dredgings extended-namely, to the northern extremity of the Bay of Biscay; and it becomes a question of high interest whether an extension of the same mode of exploration would not bring them up from the abysses of even intertropical seas.

Now, as there must have been deep seas at all geological epochs, and as the physical forces which maintain the oceanic circulation must have been in operation throughout, though modified in their local action by the particular distribution of land and water at each period, it is obvious that the presence of Arctic types of animal life in any marine formation cannot be accepted as furnishing evidence per se of the general extension of glacial action into temperate or tropical regions. How far the doctrines now current on this point may need to be modified by the new facts now brought to bear on them, it will be for geoIogists to determine; the question may be left in their hands with full assurance of a candid reception of the fresh evidence now adduced.

The general results of the dredging operations carried on during the Porcupine expedition will now be concisely stated.

In the first place they show conclusively that there is no limit to the depth at which animal life may exist on the ocean-bed; and that the types found at even the greatest depths may be not less elevated in character than those inhabiting shallower waters. It would even be premature yet to affirm that the higher types occur in less abuindance and variety than at more moderate depths ; for it is by no means impossible that the use of the improved method of collection devised by Captain Calver, ${ }^{*}$ which was employed with extraordinary success in the third cruise, may make as large an addition to our knowledge of the life of the sea-bottom explored by the dredge in the first and second cruises of the Porcupine, as it has done in the case of the cold area, where it revealed the astonishing richness of the bottom, which the Lightning dredgings of the previous year had led us to regard as comparatively barren.

Secondly, they confirm our previous conclusion that temperature exerts a much greater influence than pressure on the distribution of animal life. Not only have we found the same forms presenting themselves through an enormotis vertical range-no amount of fluid pressure being incompatible with their existence - but we have also, by a more complete survey of the relations of the warm and cold areas, established the very marked difference between the faune of two contiguous portions of the seabed lying at the same depth, which was indicated by the Eightning dredgings. It is remarkable, however, that this difference showed itself more in the crustaceans, echinoderms, sponges,

* This consists in the attachment of "hempen tangles" to the dredging ocean is szeept as well as scraped. These tangles often came up loaded, when the dredge was empty. 
and foraminifera, than it did in the mollusca, of which a considerable proportion were common to both areas. The abundance and variety of animal life on a bottom of which the temperature is at least $2^{\circ}$ (Fahr.) below the freening-point of fresh water, is a fact which has all the interest of surprise; and it is scarcely less remarkable that the forms of mollusks, echinoderms, and sponges, which seem to be the characteristic inhabitants of this cold area, should attain a very considerable size. The precise limitation of the Globigerina-mud and of the vitreous sponges to the warm area, was a very striking manifestation of the influence of temperature, ard has very important geological bearings.

Thirdly, they have largely added to the number of cases in which types that had been regarded as characteristic of earlier geological periods, and to have long since become extinct, prove to be still existing in the depths of the ocean; and greatly increase the probability that an extension of the like method of research to more distant localities would produce even more remarkable revelations of this character.

The doctrine propounded by Professor Wyville Thompson, in the report of the Lightning expedition, as to the absolute continuity of the cretaceous formation with the deposit of globigerina-mud at present in progress on the North Atlantic sea-bed, has received such striking confrmation from the discovery of the persistence of numerous cretaceous types, not merely in our own explorations, but also in those carried on by the United States Coast Survey in the Gulf of Mexico, that it may be fairly affirmed that the onus probandi rests upon those who assert that the formation of true chalk has. ever been interrupted since the cretaceous period. That period is usually considered to have terminated with the elevation of the cretaceous deposits of the European area into dry land. But according to the accepted doctrines of geology, it is highly probable that, coincidently with the elevation of the European area, there was a gradual subsidence of what is now the Atlantic sea-bed; so that the Globigerince of the former area, with many accompanying types of animal life, would progressively spread themselves over the latter, as its conditions became favourable to their existence. And there seems no reason why they should not have maintained themselves in its deepest parts, through the comparatively small changes of level which took place in this portion of the earth's crust during the Tertiary epoch.

Fourthly, the Porcupine explorations have enormously extended our knowledge of the British marine fauna; alike by the discovery of new types, and by the addition of types previously known only as inhabitants of other localities. - The mollusca alone have as yet been fully examined; and Mr. J. Gwyn Jeffreys, whose authority upon this part of the subject is not second to that of any other naturalist, reports as follows:-The total number of species of marine mollusca enumerated in his recently completed "British Conchology" (excluding the Nudibranchs) is $45 \mathrm{I}$; and to these the Porcupine expedition has added no fewer than II 7 , or more than one-fourth. Of these as many as fifty-six are undescribed, whilst seven were supposed to be extinct as Tertiary fossils. Sixteen genera, including five which are undescribed, are new to the British seas. "All that I can do," he says, "by continual dredgings in comparatively shallow water during the last sixteen years was to add about eighty species to the number described. by Forbes and Hanley. I regard the present (although a large) addition as merely an earnest of future discoveries. In fact the treasury of the deep is inexhaustible." The complete examination of the crustacea, which are in the hands of the Rev. A. M. Norman, and of the annelids, which have been undertaken by $M$. Claparède and Dr. Macintosh, will probably yield results scarcely less striking. It is, however, in the echinoderms and sponges, which are being examined by Professor Wyville Thomson; in the stony corals, which have been referred to Dr. P. M. Duncan; and in the foraminifera, which constitute the speaker's own speciality, that the most interesting novelties present themselves.

W. B. Carpenter

\section{SCIENTIFIC SERIALS}

The February number of the American Naturalist (Vol. iii. No. 12) contains only three original articles, and of these the first and most important is really: a reprint of Professor Wyman's observations on the development of the thornback, with a few introductory remarks on the natural history of the skates, by Mr. F. W. Putnam. The other two are the continuation of Mr. J. A. Allen's notes on the rarer birds of Massachusetts, and a paper on common fresh-water shells, by Mr. E. S. Morse. Professor Williamson's article on Bathybius is reprinted from the Popular Science Revico.

A SHORT paper appears in the last number of Tröschel's Archiv fuir Natzergeschichte from the pen of Dr. A. A. Krohn, on the earliest development of the Botryllus stock, which; as most of our readers are probably aware, constitutes one of the Tunicate Molluscs analogous to the misshapen bodies found so commonly on our sea coasts, and known as " dead men's fingers." Hitherto certain processes found at the anterior end of the larva have been regarded as the germs or buds of new individuals which subsequently become completely differentiated, but M. Krohn shows that these are clavate processes, constituting the first rudiments of the blood-vessels which make their appearance soon after the metamorphosis of the larva. After a short time the vessels begin to branch, each branch terminating in a dilated cœeal enlargement resembling the calyx of the common Erica tetralix in form, and at this time a round projection appears on the right side of the body, near the heart, into which a stream of blood from the mother sets, and having circulated around it returns to its starting point. It now, curiously enough, begins, together with the mother animal, to shrink, and finally disappears, and in its place a daughter Botryllus is developed. The daughter Botryllus forms two buds, a right and a left, while itself passes through the same stages as the original mother, becoming also fluid and disappearing. The two buds of this third generation, when fully developed, have their cloacal apertures opposed, and each gives off two buds which are arranged with the parents in a circular manner, and these four buds may again give off others, and so regularly arranged systems of the animals are produced, the vascular system undergoing corresponding development and extension. The blood contains colourless corpuscles, and under certain circumstances a number of dark pigment granules present in the bodies of the successive generations, on undergoing atrophy appear to gain entrance into the circulating fluid.

THF Revue des Cours Scientifigues for the 19 th inst. contains a report lof a lecture by $M$. Claude Bernard on the history of medical science and its actual condition; of one by M. Harny, on human remains in the tertiary deposits in America, and on the theories of multiple centres of creation; and of one by Dr. Bertillon on the mortality of different departments of France.

IN the just published Proceedings of the Royal Society. of Edinburgh for the session $1868-69$, Professor Allman gives a description of Rhabdopleura, a new genius of Polyzoa. The conæcium or common stem consists of a branched tube partly adherent and partly free, the free portion forming tubes of egress through which the polypides move in the acts of exsertion and retraction. In the walls of the adherent portion a rigid chitinous rod is developed along their attached side, from distance to distance, each by a flexible cord or funiculus. The polypides are hippocrepian, and each carries a shield-like process on the hæmal side of its lophophore, external to the tentacular series. In development the polypide at an early stage is included between two fleshy plates on the right and left sides respectively, and which are partially united. For some time the two plates keep pace with the general development of the bud, but ultimately they cease to increase in size, and then remain as the shieldlike processes carried by the lophophore of the polyzoon. Professor Allman regards these plates as representing the right and left lobes of the mouth in a Lamellibranchiate Mollusk, from which it follows that the relations of the Polyzoa are more intimate with the Lamellibranchiata than with the Brachiopoda, with which of late years they have been associated, but whose mantle lobes lie dorsally and vertically, instead of lying right and left as in the Lamellibranchiata. The lophophore of the Polyzoa he considers to have. its representative in the labial palps of the Lamellibranchiata. The animal was obtained by the Rev. A. Norman and Mr. J. Gwyn Jeffreys in the course of deep-sea dredging in Shetland.

THE Fournal of the Chemical Society for February is mainly occupied by a long paper by Mr. F. A. Abel, entitled "Contributions to the history of explosive agents," abstracted from the Philosophical Transactions for 1869 . There are also shorter articles on nontronite, and on a new chromium oxychloride, by Dr. T. E. Thorpe, and observations on the solution of gases in water by Dr. Williamson.

THE Monthly Microscopical Fournal for March contains the Presiclent's Address, an obituary notice of the late J. J. Lister, F.R.S., and articles on the structure of the stems of the arborescent Lycopodiacee of the coal measures, by Mr. Carruthers, and on the mode of examining the microscopic structure of plants. 